\section{A renovação da linguagem jornalística no jornalismo} em quadrinhos

The renewal of the journalistic language in the comics journalism

\author{
Roberto Elísio dos Santos ${ }^{[a]}$, Deise Cavignato ${ }^{[b]}$
}

\section{Resumo}

Técnica empregada há muito tempo nos jornais impressos, as histórias em quadrinhos como atividade jornalística vêm ganhando autonomia e destaque na atualidade. O jornalismo em quadrinhos apropria-se de elementos literários, como o new journalism já havia feito anteriormente. Por esse motivo, analisamos uma história sequencial que contém tais recursos linguísticos, além de identificarmos as modificações da linguagem como fator de inovação do texto jornalístico. Trata-se de uma pesquisa qualitativa, de nível exploratório, cujos objetos de estudo foram os livros Loucas de Amor e Loucas de [a] Jornalista, doutor em Ciências da Comunicação pela Universidade de São Paulo (USP), pós-doutorado em Comunicação pela mesma universidade, professor da Escola de Comunicação e do Programa de Pós-Graduação em Comunicação da Universidade Municipal de São Caetano do Sul (USCS) e vice-coordenador do Observatório de Histórias em Quadrinhos da ECA-USP, São Caetano do Sul, SP- Brasil, e-mail: roberto.elisio@uscs.edu.br

[b] Jornalista, mestre em Comunicação pelo Programa de Pós-Graduação em Comunicação da Universidade Municipal de São Caetano do Sul (USCS), São Bernardo do Campo, SP-Brasil, e-mail: deisecavi@yahoo.com.br

Palavras-chave: Histórias em quadrinhos. Jornalismo em quadrinhos. Linguagem jornalística. 
Amor em Quadrinhos, mais especificamente a história Os Jacks, com roteiro do jornalista Gilmar Rodrigues e desenhos do cartunista Fido Nesti, que foi analisado a partir do referencial da semiótica da cultura. O objetivo deste trabalho é identificar as transformações da linguagem jornalística nesses dois formatos (jornalismo literário e jornalismo em quadrinhos). Como resultado, pode-se afirmar que os formatos jornalísticos aqui estudados e analisados diferenciam-se conforme suas formas específicas, mas ainda mantêm algumas características comuns.

\section{Abstract}

Technique used for a long time in printed newspapers, comics as a journalistic activity is gaining prominence and autonomy in current days. The comics journalism appropriates literary elements, in the same way the new journalist had done previously. Therefore, we analyze a sequential story that contains such language resources, and we identify the language modifications as a factor of innovation of the journalistic text. This is a qualitative research, with an exploratory level, whose objects were the books Loucas de amor e Loucas de amor em quadrinhos, especially the history Os Jacks, written by journalist Gilmar Rodrigues and illustrated by the cartoonist Fido Nesti. The objective of this work is to identify the transformation of journalistic language in these two formats (literary journalism and comics journalism). As result, it can be argued that the journalistic formats studied and analyzes here differ according to their specific forms, but they still retain some common characteristics.
Keywords: Comic. Comics journalism. Journalistic language.

\section{Introdução}

Este artigo científico tem o intuito de identificar as transformações da linguagem jornalística em histórias em quadrinhos baseadas em fatos reais, partindo-se do pressuposto de que a $\mathrm{HQ}$ (história em quadrinhos) 
utiliza recursos literários para informar o leitor. Fundametados nisso, abordamos as técnicas jornalísticas, os veículos de comunicação, principalmente, o livro-reportagem, o hibridismo entre os discursos literários e jornalísticos, além da fronteira entre o real e o ficcional e os recursos imagéticos no jornalismo.

Para elucidar as informações referentes ao jornalismo em quadrinhos, discutimos o assunto da relação da imprensa com as HQs, da linguagem dos quadrinhos e dos quadrinhos autobiográfico e biográfico. A análise de conteúdo foi feita com base na Teoria Semiótica Russa relacionando-se aos signos trabalhados com a modelização, os códigos culturais e os sistemas de linguagem. Os objetos de estudo são os livros Loucas de Amor e Loucas de Amor em Quadrinhos, o primeiro é um livro-reportagem de teor literário e o segundo, uma história em quadrinhos jornalística.

\section{Jornalismo e linguagem}

$\mathrm{Na}$ linguagem jornalística são trabalhados diversos conceitos para que o público entenda, de forma clara e objetiva, um assunto que será abordado. Logo no início das aulas de um curso de Comunicação Social com habilitação em Jornalismo, os estudantes aprendem como devem escrever e transmitir determinada mensagem de acordo com uma construção narrativa e técnicas "engessadas". Um exemplo bem comum é o lead que utiliza o que chamamos de pirâmide invertida, fazendo com que as principais informações da notícia sejam respondidas logo no primeiro parágrafo: o quê, quem, quando, onde, como, por quê. Ou seja, o Jornalismo atua com informações coletadas na apuração de uma história e dificilmente pode ser escrito da maneira como o repórter achar conveniente. Infelizmente é recorrente deixar a estilização própria de lado e, cada vez mais comum, abdicar-se do estilo pessoal, conforme o que é ensinado didaticamente nas instituições de ensino.

De acordo com Costa e Ribeiro (2009, p. 30), nem sempre o jornalismo foi feito dessa forma:

Com a crescente profissionalização do jornalismo no decorrer do século $X X$, a atividade jornalística começou a se distanciar do discurso literário - processo que se desencadeou especificamente na primeira metade desse século - , e o jornalismo foi gradativamente adquirindo um discurso próprio, autêntico, autônomo, cada vez mais independente do 
discurso literário. As redações, antes ocupadas majoritariamente por literatos, hoje vivem povoadas por graduados hábeis em praticar fórmulas prontas de construção textual aprendidas nas faculdades, que, muitas vezes, nem são aprendidas, mas apenas apreendidas e replicadas (COSTA; RIBEIRO, 2009, p. 30).

Para Andretta (2008), a fusão entre literatura e jornalismo era bem vista, inclusive com a influência machadiana na literatura brasileira; afinal, os romances de Machado de Assis nasceram nesses veículos. Já a linguagem jornalística é concebida de maneira fria e objetiva, com notícias curtas para que os leitores consigam ler as matérias até o fim. Diante de tantos entrelaçamentos e desencontros, surgiu o New Journalism ou Novo Jornalismo na década de 1960, nos Estados Unidos, e que se mostrou contrário às técnicas utilizadas como padrão jornalístico e se uniu ao Jornalismo Literário. Para Lopes $(2010$, p. 3), esse movimento era de "renovação estilística, ideológica e funcional", além de defender o "jornalismo de autor".

Vitor Necchi (2009, p. 104) lembra-nos de que jornalismo literário não é sinônimo de New Journalism, pois este último foi, de acordo com ele, uma fase do jornalismo literário que estendeu seu reconhecimento com as obras dos autores Truman Capote, Norman Mailer, Gay Talese e Tom Wolfe. Elementos literários em jornais de grande porte são escassos. "Os dirigentes dos jornais costumam alegar equipes reduzidas, falta de espaço para textos caudalosos, orçamentos minguados a impedir que um repórter permaneça semanas ou meses investigando uma história", afirma Necchi (2009, p. 106).

O New Journalism também influenciou os veículos de comunicação brasileiros. De acordo com Oliveira (2010), os periódicos que mais tiveram expressão foram a revista Realidade e o Jornal da Tarde, ambos lançados em 1966. "Essa experiência jornalística fez com que as tiragens dobrassem no período de um ano. Porém, esse sucesso editorial dos dois veículos durou cerca de dois anos, começando a perder forças até encerrar as suas atividades" (OLIVEIRA, 2010, p. 38).

Com ínfimos espaços para fluir textos jornalísticos com viés literário, a solução é a utilização de outro veículo: o livro-reportagem. No Brasil, Oliveira (2010, p. 41) afirma que o livro-reportagem teve grande repercussão devido à censura imposta pela ditadura militar, pois "a literatura não recebia uma atenção rigorosa: a população não tinha o hábito e nem uma renda que propiciasse adquirir livros. Ele foi, dessa forma, um meio de fuga dos jornalistas que queriam denunciar e repassar a realidade presenciada". 
Para melhor exemplificar como o jornalismo se apropria de elementos literários e como a literatura toma posse de recursos jornalísticos, Oliveira (2010) relata que o jornalismo utiliza a narração para repassar as informações, além de utilizar recursos literários para falar ou descrever sobre os personagens e os ambientes, por exemplo. Já a literatura também pode empregar dados atuais, além de nomes e declarações reais.

No jornalismo, muitos profissionais utilizam elementos literários para informar o seu público, bem como, na literatura, escritores incorporam elementos jornalísticos para a construção e também no conteúdo de sua obra. É nesse momento que os dis-cursos se aproximam e os gêneros "dialogam" (OLIVEIRA, 2010, p. 30).

Deve-se debater sobre fronteira entre o real e o ficcional, pois o literário tem abordagens distintas às do jornalismo, porém grande parte desse território demonstra que as diferenças podem ser pequenas. De acordo com Andretta (2008), "jornalismo literário é o relato baseado no real, no fato jornalístico, com as apurações e entrevistas próprias das técnicas dos periodistas, mas com o capricho da linguagem dos escritores, com a arte dos literatos" (ANDRETTA, 2008, p. 106). Sendo assim, é possível entender que o jornalismo literário é feito com informações reais, mas escrito de maneira rebuscada como os literatos faziam. Já para Pena (2006, p. 103), “o factício no Jornalismo Literário não se baseia na veracidade, mas sim na verossimilhança, ou seja, na mimetização da realidade".

O ponto de vista de Pena é interessante ao concordar que o jornalismo literário utiliza recursos inspirados na literatura como: "imersão do repórter na realidade, voz autoral, estilo, precisão de dados e informações, uso de símbolos (inclusive metáforas), digressão e humanização" (PENA, 2006, p. 105). Entretanto, mais interessante é o modo como Pena (2006, p. 114-115) informa que nem mesmo o jornalismo pode ser aplicado à total realidade: ao presenciar uma cena e narrar o fato à outra pessoa, o narrador filtra o que acredita não ser tão importante e relata apenas o que desperta a curiosidade do ouvinte, ou seja, é impossível contar uma história sem alterações, mesmo que o narrador seja o mais fiel possível à realidade.

As ilustrações jornalísticas servem para "quebrar" a seriedade de uma matéria, valendo-se de uma forma criativa na utilização de infográficos e vinhetas. Pode apresentar novos dados ou corroborar o que é dito na matéria. Alexandre Barbosa (2011) destaca, a partir de Paiva 
(2002), a importância da iconografia aos historiadores para narrar fatos e momentos históricos.

Ela [iconografia] é uma das fontes mais ricas para isso, na qual podemos encontrar as escolhas do produtor desta iconografia e todo o contexto em que foi concebida, idealizada, forjada ou inventada. Mas, quando tomadas como um retrato fiel de um período, as imagens também podem se tornar armadilhas para os narradores. Faz-se necessária, portanto, a leitura minuciosa da imagem para interpretação de uma época, não apenas pelo seu conteúdo primeiro, como também pelas circunstâncias que cercam sua produção (BARBOSA, 2011, p. 77).

Para discutir as histórias em quadrinhos como recurso jornalístico, damos exemplos que comumente aparecem em jornais como a simulação, que pode ser a ilustração do cenário onde ocorreu um assassinato ou da sequência de ações de criminosos. Os últimos momentos da vítima são essenciais para a investigação, pois auxiliam na compreensão dos fatos e tentam revelar possíveis contradições dos autores envolvidos no crime. Sendo assim, uma vez que não é possível fazer reconstituição com fotos, já que ninguém presenciou o acontecimento, a simulação do crime é desenvolvida por meio de imagens que supõem o ocorrido.

A prática de combinar quadrinhos com fatos reais remota ao século XIX, quando Ângelo Agostini, um italiano que viveu no Brasil, ilustrou situações que ocorriam cotidianamente. Em 1985, houve um acidente na estrada de ferro de São Paulo e Agostini desenhou a queda do trem em uma vala e o socorro aos feridos prestado pelos frades de um seminário local.

É possível dizer que nas narrativas são demonstrados sentimentos do autor e dos entrevistados em diálogos, depoimentos e, ainda mais, nas imagens ilustradas. Como diz Belo (2006, p. 118), "escrever uma reportagem não é enumerar fatos mecanicamente, mas sim dar vida a uma história real". O autor continua:

A missão da reportagem é contar uma história com começo, meio e fim, que informe e emocione o leitor - seja pelo encantamento ou pela indignação. O relato sempre pode e deve recorrer a alguns artifícios para fugir do padrão tradicional da notícia como se pratica no Brasil: lead, sublead, texto seco, sem adjetivos, uso da pirâmide invertida etc. A informação tem de estar lá, mas o modo como ela se apresenta não precisa constar de nenhum manual. O importante é que ele cumpra a sua função (BELO, 2006, p. 123). 
Mais uma prova de que a ilustração já fazia parte do mundo jornalístico veio com o gonzo jornalista Hunter Thompson (1937-2005), que, diferentemente de todas as formas de jornalismo, exige um envolvimento pessoal do autor com o acontecimento. $O$ repórter se insere como um personagem na história e narra os fatos do seu ponto de vista e não são raras as vezes em que os jornalistas utilizam algum tipo de droga, bebida alcoólica ou alguma substância ilícita, para influenciar a sua escrita. É nesse contexto que Thompson "costumava fazer-se acompanhar não de um fotógrafo, mas de um ilustrador. Uma lente seria realista demais. Então, o desenhista Ralph Steadman dava-lhe um gênero de apoio que nenhum fotógrafo daria, o de adaptar-se perfeitamente ao texto" (RIBEIRO, 2012, p. 1). Diante disso, torna-se perceptível a ligação entre o desenho e a reportagem.

\section{Histórias em quadrinhos: consolidação e linguagem}

As histórias em quadrinhos (HQs) têm um longo histórico relacionado ao jornalismo, pois as primeiras publicações das HQs foram em jornais impressos, que inclusive utilizavam este recurso para atrair mais leitores. O quadrinho foi uma forma de linguagem que surgiu para comercializar mais jornais, principalmente com o surgimento de Yellow Kid, uma história em quadrinhos que fez sucesso tendo como principal atração um garoto que usava um roupão amarelo. Com a atenção dos leitores voltada aos quadrinhos, os jornais fizeram mais sucesso, havendo, inclusive, disputa de quadrinhos entre os periódicos. Segundo Johnny Vargas Durán, o Menino Amarelo nasceu em 1895 "em meio à luta entre dois magnatas dos jornais, William Randolph Hearst e Joseph Pulitzer. Hearst tinha chegado naquele mesmo ano a Nova York e logo percebeu a importância de suplementos utilizados como pagamento pela venda do seu jornal de domingo" (DURÁN, 1999, p. 1, tradução nossa).

Servindo para fomentar a competição entre empresas jornalísticas, os quadrinhos ganharam força mercadológica, tendo crescimento inclusive internacional. Os jornais impressos que tinham o dever de publicar notícias corriqueiras, artigos e notas ampliaram o espaço para um novo modelo que surgia, os quadrinhos, e trazia consigo grande expectativa dos leitores, seja para tiras engraçadas ou sátiras focadas nos acontecimentos cotidianos.

As histórias em quadrinhos também surpreenderam quando foram utilizadas por outros meios, que não a mídia, para transmitir dados, informações e ressurgir como marketing para muitas empresas. Sindicatos 
empregaram desenhos para dar informações a respeito de suas reivindicações; os governos, assim como o Ministério da Saúde, fizeram campanhas com cartilhas sobre educação sexual para jovens; quadrinhos na educação também já não são novidade; o setor de transportes também se aproveitou da linguagem para mostrar a importância da sinalização de trânsito, e assim por diante.

Tudo isso evidencia o potencial das histórias em quadrinhos para atingir todas as camadas da população. Da mesma forma, essa utilização evidencia a popularidade do meio na sociedade, distinguindo o potencial como um dos mais conhecidos, ainda que nem sempre aceito por todo o público (VERGUEIRO, 2009, p. 84).

Cabe aqui destacar os elementos utilizados nos quadrinhos como artifício de linguagem deste meio de comunicação: balão, onomatopeia, recordatório, requadro, linhas cinéticas e metáforas visuais. Santos (2002) trata o balão como um indicador ao leitor que mostra qual personagem está falando por meio de "um apêndice denominado rabicho [...] que se projeta em direção à cabeça ou à boca do personagem que fala" (SANTOS, 2002, p. 21). Além da fala, os balões revelam o pensamento da personagem, se está gritando ou falando em voz baixa, demonstrando sentimentos como a raiva, por exemplo, com o uso de linhas e formatos de cada balão. O recordatório é apresentado como painéis inseridos no quadrinho com texto, isto é, para essa ação não é necessário haver balões de fala. Já as onomatopeias são formas de representar os ruídos com palavras como, por exemplo, SOC e POW (soco), BANG (tiro), TOC TOC (batendo na madeira ou na porta) e ZZZZZZZ (ressonar).

Linhas cinéticas servem para indicar movimento dos personagens ou de objetos, pode ser um menino jogando futebol ou um carro em movimento. Santos (2002) também explica que a metáfora visual é "quando a imagem se associa a um conceito diferente de seu significado original", veja seus exemplos: "ver estrelas, ter o coração em festa, sentir a cabeça rodar, roncar como uma serra" (SANTOS, 2002, p. 23).

E o último recurso visual encontrado nos quadrinhos é o requadro.

Cada momento, expresso por meio de uma ilustração, recebe o nome de vinheta. A maior parte das vinhetas, que contém as ações apresentadas em ângulos (câmera alta ou baixa) e planos (médio, close-up etc.), é circundada por linhas, denominadas de requadro, um elemento visual que 
também pode se revestir de uma significação, exercendo uma função metalinguística (SANTOS, 2002, p. 20)

Além de entretenimento, os quadrinhos podem ser usados na educação, na publicidade e também no jornalismo. Neste trabalho, conceituamos a história em quadrinhos jornalística quando o quadrinista faz uma $\mathrm{HQ}$ com enfoque jornalístico; já o jornalismo em quadrinhos é quando o jornalista faz a HQ utilizando a linguagem da nona arte para fazer uma reportagem. O jornalista Joe Sacco é quem de fato inicia o jornalismo em quadrinhos, pois foi com os seus livros voltados às guerras que ele mostrou ao mundo a maneira de fazer um livro-reportagem inovador e atraente, no qual se espelharam vários jornalistas posteriormente. Algumas das suas obras são: Palestina (1996), Área de Segurança: Gorazde (2000) e O Mediador: Uma História de Sarajevo (2003).

O francês Didier Lefrève seguiu os passos de Joe Sacco em seu livro O Fotógrafo (2003) sobre os Médicos Sem Fronteiras (MSF). Lefrève acompanhou a equipe e tirou fotos profissionais para contar o dia a dia dos médicos que tratavam os refugiados de guerra no Afeganistão. Nesse caso, Lefrève tirou as fotos e as utilizou no livro como recurso em vez de fazer o livro inteiro em quadrinhos; portanto, as páginas dos três volumes da obra mesclam ilustrações e fotos com legendas em vez de balões nas imagens fotográficas.

Já as autobiografias em quadrinhos não são consideradas jornalismo, pois os autores contam as suas próprias histórias, não tendo sido necessário se basear em documentos ou, até mesmo, entrevistar outras pessoas. Partindo do ponto de vista do autor, a história desenrola-se continuamente, apresentando o que lhe aprouver.

Podemos ser razoavelmente céticos de que as pessoas vão ser honestas e verdadeiras sobre si mesmas. Se descobrirmos que uma autobiografia ou memórias, ou, Deus nos livre, uma obra de jornalismo é embelezada ou falsificada, reagimos negativamente. Isso faz diferença para nós. Fundamentalmente, nos sentimos enganados. [...] Ficção cria um mundo imaginário e busca a verdade emocional, mas que não tem nenhum requisito firme para os detalhes preocupantes do mundo real, como faz jornalismo literário (SIMS, 2009, p.14, tradução nossa).

Um exemplo de autobiografia é o livro de Marjane Satrapi, Persépolis (2007), em que narra a sua vida passada na cidade de Teerã, capital do 
Irã, relatando os costumes daquele local e os acontecimentos do final da década de 1970. Expõe suas ideias infantis e juvenis e fala da ditadura imposta pelo Xá e as dificuldades do povo vividas naquele momento.

Entre as biografias tem-se Maus (2005), livro escrito e desenhado pelo ilustrador Art Spiegelman, que conta a história do pai de Art, um judeu polonês que sobreviveu ao campo de concentração de Auschwitz. Em vez de desenhar humanos, Spiegelman retratou os judeus como ratos e os nazistas como gatos; ele utilizou a metáfora para instigar os leitores. Até hoje Maus é a única obra em quadrinhos que ganhou o Prêmio Pulitzer de literatura americana.

\section{Análise de quadrinho jornalístico}

Neste trabalho apresentamos uma história de ambos os livros que são objetos deste estudo, intitulada Os Jacks. Na introdução do livro, o autor Gilmar Rodrigues afirma que esta história é factual e segue informações rigorosas sem ter sido modificada. 0 jornalista que escreveu o livro realizou um trabalho de campo e entrevistou diversos criminosos sexuais em presídios do estado de São Paulo para checar se os detentos tinham mulheres, namoradas ou até mesmo amantes.

Os entrevistados disseram que os presos enviavam cartas e anúncios aos jornais para conseguirem namoradas; outras vezes, algumas mulheres eram apresentadas por outras que já visitavam os presidiários. A história termina com um samba nas vozes dos prisioneiros, classificado na obra como "da melhor qualidade. De conceito. A galera fez coro e mandou ver na batucada" (RODRIGUES, 2009, p. 24). O autor utilizou, inclusive, gírias como "o papo rolou solto" (ver Figura 1). Com relação a essa linguagem, Preti (1998 apud RAMOS, 2009, p. 43) afirma que "houve um inesperado prestígio social da linguagem popular, em especial na década de 1990. A gíria até então tida como marginal e contestadora da norma seguida pela grande massa, é gradativamente incorporadora ao vocabulário nacional". Para Ramos (2009), o caminho da gíria é migrar do oral para o escrito, sendo que os quadrinhos são uma das principais fontes que reproduzem essa linguagem popular.

É importante ressaltar que os quadrinhos, em consonância com o texto literário, permitem o surgimento de novos sistemas de organização. De acordo com Machado (2003), a junção de diversos textos da cultura pode fazer emergir um novo sistema. "No espaço semiótico, muitos 


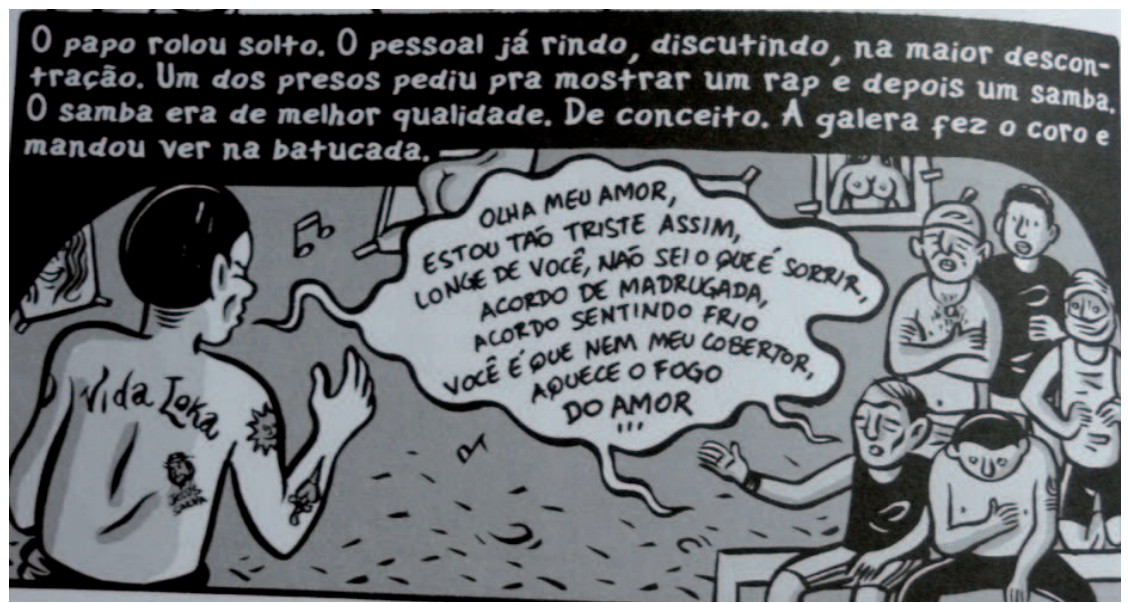

Figura 1 - Quadro da história Os Jacks com escrita literária e gíria no recordatório

Fonte: Extraído de RODRIGUES, 2009.

sistemas se chocam com outros e mudam repentinamente seu aspecto e sua órbita. $O$ choque, contudo, não destrói, mas mostra a possibilidade de transformação do sistema", afirma Machado (2003, p. 42).

A narrativa é em primeira pessoa e logo no primeiro parágrafo o autor revela fatos pessoais como "Por que eu, um cara com uma filha pra criar e emprego estável, resolveu se meter nessa história de ir atrás de estupradores e mulheres de estupradores?" (RODRIGUES, 2009, p. 17). Nesse contexto, Rodrigues se apropria do jornalismo literário, escrevendo de forma autoral e pessoal em um formato de quadrinhos. Apesar de o autor não considerar a obra Loucas de Amor um livro literário, ele concorda que em alguns momentos utiliza a linguagem literária em descrições mais subjetivas dos ambientes e personagens, com impressões e observações pessoais. Para Gilmar Rodrigues, em entrevista concedida aos autores em 5 de novembro de 2012, o jornalismo usa elementos literários, bem como a literatura se apossa de recursos jornalísticos:

Eu mesmo tentei me apropriar (não sei se fui bem sucedido) em algumas passagens do livro, da linguagem literária [...]. O oposto também é verdadeiro, têm várias obras que partem de fatos reais, de personagens reais ou com fundo histórico... A literatura tem que ter uma 'verdades última, uma base em histórias identificáveis sejam pessoais, sejam coletivas, fatos históricos, mas com um fundo que poderíamos chamar de 
jornalístico (ou seja, fatos que se não aconteceram na (realidade) poderiam ter acontecido) 1 .

Essa imersão do autor na história também se aprofunda ao longo da narrativa, mostrando inclusive os seus pensamentos no recordatório dos quadrinhos, isto é, os painéis inseridos na ilustração (ver Figura 2). Em alguns instantes o recordatório aparece em um quadrado e em outros o formato é ondulado, mas esses recursos foram usados sem critério lógico nas cenas.

Na Figura 2, aparece a palavra "bunda", uma linguagem coloquial que é empregada intencionalmente e aparece com certa frequência nessa e em outras narrativas da obra. Em certo momento, Rodrigues achou importante explicar um termo que aplicou no texto, a palavra "rapaziada", colocando entre parênteses a frase "não se pode chamar eles de moçada, pois trata-se de rapazes, não de moças" ${ }^{2}$. Suas opiniões também são expressas como na frase "havia caras de todos os tipos; até uns tiozinhos com cara mais inofensiva do mundo. [...] Ninguém tem etiqueta de tarado" (RODRIGUES, 2009, p. 18). Segundo o jornalista, ele "não quis ficar indiferente a acontecimentos tão perturbadores, tão inacreditáveis":

Se eu fizesse isso seria falso, burocrático, frio, é impossivel qualquer ser humano com o mínimo de sangue nas veias não opinar, não ter impressões e observações sobre um assunto tão quente como esse. Procurei deixar bem claro as minhas interpretações. Pra mim o jornalismo nunca é completamente isento, é impossivel isso. Melhor assumir as opiniões do que se esconder atrás de uma 'objetividade' que pra mim é falsa3.

Os dois profissionais também visitaram outra cadeia e resolveram levar um "jumbo", ou presente, para os prisioneiros para que eles se entrosassem com mais facilidade e falassem sobre as visitas íntimas, as correspondências trocadas por eles com as mulheres e como eles conheciam outras pessoas estando atrás das grades. Mais uma vez o jornalista escreve coloquialmente, mostrando sua inquietação de comprar cigarro para os detentos (Figura 3).

1 Entrevista realizada pelos autores do artigo por e-mail no dia 5 nov. 2012.

2 Entrevista realizada pelos autores do artigo por e-mail no dia 5 nov. 2012.

3 Entrevista realizada pelos autores do artigo por e-mail no dia 5 nov. 2012. 

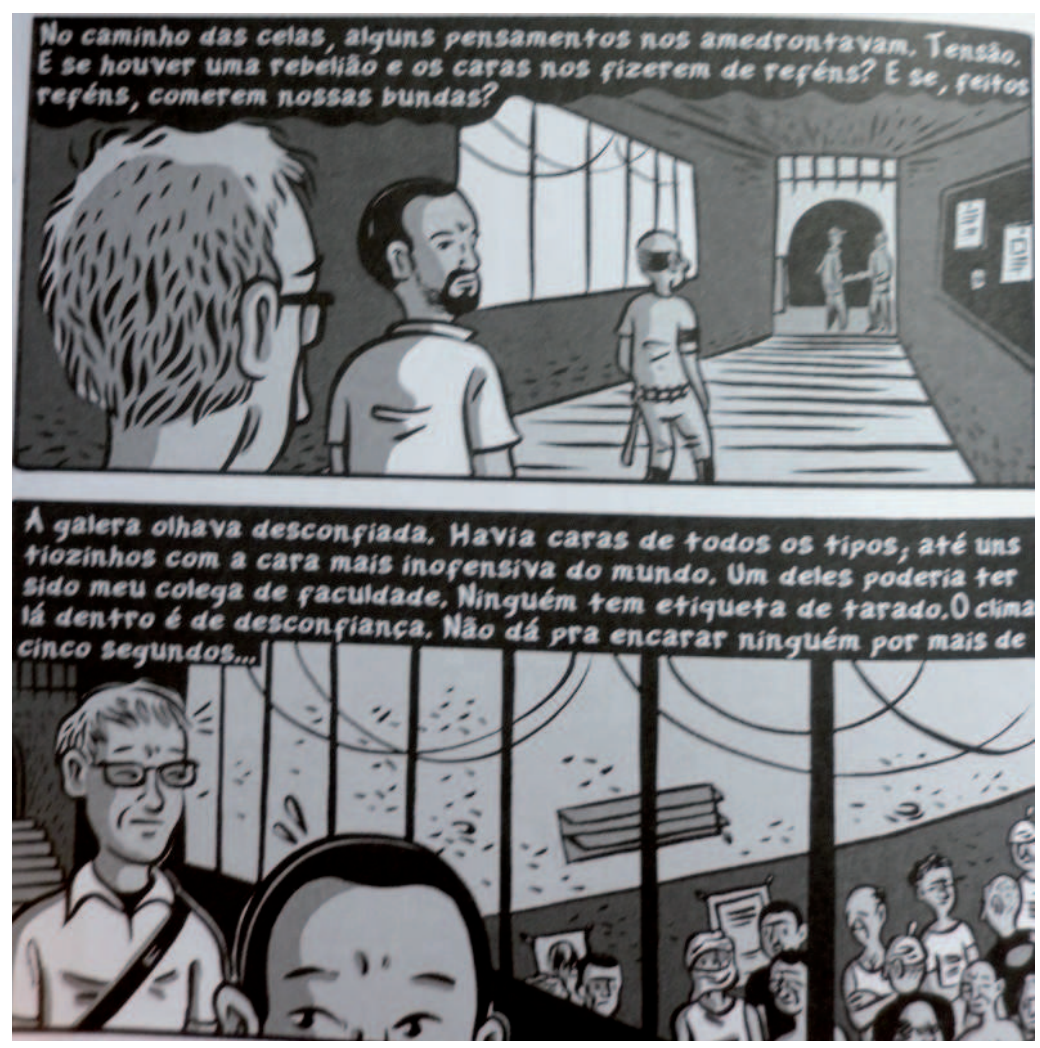

Figura 2 - Cenas da história mostram de forma coloquial os pensamentos dos envolvidos Fonte: Extraído de RODRIGUES, 2009.

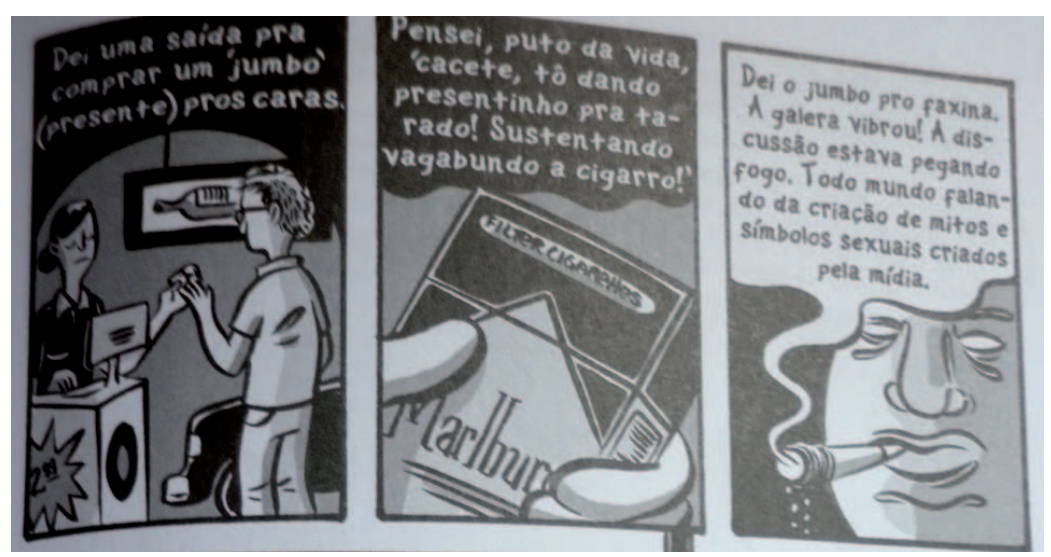

Figura 3 - llustração com uso da coloquialidade - palavras como "puto da vida" e "jumbo pro faxina" - além da fumaça do cigarro utilizada como balão

Fonte: Extraído de RODRIGUES, 2009. 
Na Figura 3, é possível ver que o recordatório foi substituído pela fumaça do cigarro, pois o ilustrador utilizou um recurso de quadrinhos para contar a história, fazendo com que a narração passasse dentro da fumaça. A estruturalidade de uma história em quadrinhos, obviamente, é diferente de uma história literária, na qual não é preciso ter ilustrações para entender o que a história quer passar, já a HQ não teria sua estruturalidade sem os desenhos. Para Machado (2003, p. 158), a estruturalidade é:

Dinamismo modelizante que garante a organização de um sistema semiótico como linguagem, ainda que não possua uma língua, ou seja, uma estrutura regulada por um código definido. [...] Estruturalidade é a qualidade textual da cultura sem aquela as mensagens não podem ser reconhecidas, armazenadas, divulgadas.

Diante da Figura 3, podemos ver que o desenhista ilustrou a caixa de cigarros com a marca "Marlboro", porém com o nome "Marlburo", fazendo uma alusão à marca existente no mercado. Esse modo de representar os produtos de marca é utilizado em várias histórias da obra.

Outro ponto crucial observado é que o ilustrador Fido Nesti optou por desenhar o jornalista e o roteirista na cena, sendo um caso de voz autoral, elemento do jornalismo literário, pois os autores contam os acontecimentos por meio do seu olhar. Para Gilmar Rodrigues, o que está nos quadrinhos são os bastidores da pesquisa, propício para a aparição do autor:

Resolvi contar os bastidores em HQ para deixar as minhas impressões e sensações bem pessoais fora do texto já que a história das mulheres é muito mais forte do que a minha história. Ficar me colocando na primeira pessoa, no texto, seria uma egotrip total, um fracasso, pois iria concorrer com histórias quase inacreditáveis que são as histórias das mulheres que amam serial killers. Por outro lado, achei interessante contar esses pequenos acontecimentos do cotidiano da pesquisa [...] com comentários bem humorados e pessoais ${ }^{4}$.

\section{Considerações finais}

A partir das análises, pode-se constatar que o jornalismo em quadrinhos inova o fazer jornalístico, tendo em vista que ambos os formatos

4 Entrevista realizada pelos autores do artigo por e-mail no dia 5 nov. 2012. 
(jornalismo literário e jornalismo em quadrinhos) são amplos campos de atuação, porém suas utilizações híbridas trazem um recurso diferente do habitual, tratando notícias e histórias reais como elementos inovadores.

As duas linguagens têm seus méritos próprios, no entanto a HQ apropria-se de elementos do jornalismo literário, transformando as histórias em quadrinhos em fontes de conhecimento como as que são encontradas em livro-reportagens. Essas apropriações trazem riquezas ao texto e as figuras são elaboradas de acordo com dados não ficcionais, ou seja, a veracidade não pode ser questionada por basear-se em documentos e entrevistas com fontes confiáveis.

Podemos identificar a linguagem de uma $\mathrm{HQ}$ com sua estruturalidade específica, isto é, com balões, onomatopeias, recordatórios, requadros, linhas cinéticas e metáforas visuais. Já o jornalismo literário tem seus elementos aplicados em recursos verbais como a imersão do repórter, voz autoral, estilo, precisão de dados e informações, uso de símbolos e metáforas, digressão e humanização. Diante do reconhecimento das diferentes constituições das duas linguagens, descobrimos que o jornalismo em quadrinhos também se utiliza formalmente dessas matérias-primas para produzir conteúdos jornalísticos.

Tendo em vista que as histórias em quadrinhos jornalísticas são vistas com polêmica por falta de confiança nos desenhos, devemos relembrar que não é possível acreditar totalmente no que o próprio jornalismo convencional divulga. Não se deve cobrar de uma $\mathrm{HQ}$, que é uma representação do real, algo que seja "totalmente" verídico, já que nem os próprios veículos tradicionais o são apesar de basearem-se em fatos reais.

Os signos trabalhados juntamente com a modelização e os códigos culturais foram expostos de forma constante nos livros. Acreditamos que discutir os sistemas de linguagem por meio da Semiótica da Cultura, que são dotados de inúmeros conceitos, foi o ideal para este trabalho que apontou a estruturalidade de ambos os textos.

\section{Referências}

ANDRETTA, C. B. A relação entre jornalismo e literatura em três romances-reportagens. 2008. 126 f. Dissertação (Mestrado em Teoria e História Literária) Universidade Estadual de Campinas, Campinas, 2008. 
BARBOSA, A. Os quadrinhos históricos: conceituação e desenvolvimento no Brasil e no mundo. In: VERGUEIRO, W.; SANTOS, R. E. dos. (Org.). A História em quadrinhos no Brasil. São Paulo: Editora Laços, 2011. p. 76-93.

BELO, E. Livro-reportagem. São Paulo: Contexto, 2006.

COSTA, A. V.; RIBEIRO, E. M. Estado de Minas: do jornalismo literário à escrita técnica. Conexão - Comunicação e Cultura, v. 8, n. 16, p. 29-52, jul./dez. 2009.

DURÁN, J. V. Un niño amarillo cumplirá cien años de edad. Revista Latina de Comunicación Social, v. 2, 1999.

LOPES, P. C. Jornalismo e linguagem jornalística: revisão conceptual de base bibliográfica. Lisboa: Universidade Autónoma de Lisboa, 2010.

MACHADO, I. Escola de Semiótica: a experiência de Tartú-Moscou para o estudo da cultura. São Paulo: Ateliê; Fapesp, 2003.

NECCHI, V. A (im)pertinência da denominação "jornalismo literário". Estudos em Jornalismo e Mídia, v. 6, n. 1, p. 99-109, jan./jun. 2009.

OLIVEIRA, A. S. de. Abusado e Cidade de Deus: o limite textual entre o jornalismo e a literatura. 2010. 104 f. Dissertação (Mestrado em Letras) - Universidade Federal de Santa Maria, Santa Maria, 2010.

PAIVA, E. F. História e Imagem. Belo Horizonte: Autêntica, 2002.

PENA, F. Jornalismo literário. São Paulo: Contexto, 2006.

PRETI, D. A gíria na sociedade contemporânea. In: VALENTE, A. (Org.). Língua, linguística e literatura. Rio de Janeiro: Eduerj, 1998. p. 119-127.

RAMOS, P. A leitura dos quadrinhos. São Paulo: Contexto, 2009.

RIBEIRO, M. Os primórdios do gonzo em diário de um jornalista bêbado. 2012. Disponível em: <http://miltonribeiro.sul21.com.br/tag/politica/>. Acesso em: 23 abr. 2013.

RODRIGUES, G. Loucas de amor em quadrinhos: mulheres que amam serial killers e criminosos sexuais. Porto Alegre: Idéias a Granel, 2009.

SANTOS, R. E. dos. Leitura semiológica dos quadrinhos. Revista Imes Comunicação, v. 2, n. 4, p. 19-31, 2002. 
SIMS, N. Essay - The problem and the promise of literary journalism studies. Literary Journalism Studies, v. 1, n. 1, p. 7-16, Spring, 2009.

VERGUEIRO, W.; RAMOS, P. Quadrinhos na educação. São Paulo: Contexto, 2009.

Recebido: 03/04/2013

Received: 04/03/2013

Aprovado: $27 / 05 / 2013$

Approved: 05/27/2013 